\title{
A Randomized Comparative Study of Two Different Concentrations of Ketamine and Propofol Combination in Upper Gastrointestinal Endoscopy Procedures
}

\author{
Hosni Ali Salem ${ }^{1 *}$ MD
}

\section{*Corresponding Author \\ Hosni Ali Salem \\ hosniali966@gmail.com}

Received for publication Aril 7, 2020; Accepted September 3, 2020;

Published online September 4, 2020

\section{Copyright 2020 The Author published by Al-Azhar University, Faculty of Medicine, Cairo, Egypt. All rights reserved. This an open-access article distributed under the legal terms, where it is permissible to download and share the work provided it is properly cited. The work cannot be changed in any way or used commercially. \\ doi: 10.21608/aimj.2020.27454.1191 \\ ${ }^{1}$ Department of Anesthesia and Intensive Care, Faculty of Medicine, Al-Azhar University, Cairo, Egypt.}

\begin{abstract}
Background: Ketofol is a mixture of ketamine and propofol. It is one of the agents known to achieve procedural sedation and analgesia.

Aim of the study: This prospective randomized study compared the effectiveness and safety of two doses of ketofol in morbidly obese patients undergoing diagnostic upper gastrointestinal endoscopy.

Methods: The study included 100 adult patients, American Society of Anesthesiologists II and III. The patients were divided into two equal groups; group I in which the ketamine dose equal the propofol dose $(\mathrm{k} / \mathrm{p} 1: 1), \mathrm{n}=50$, and group II in which ketamine dose equal $1 / 4$ of the propofol dose $(\mathrm{k} / \mathrm{p} 1: 4), \mathrm{n}=50$. In separate syringes, ketamine $1 \mathrm{mg} / \mathrm{kg}$ plus propofol $1 \mathrm{mg} / \mathrm{kg}$ were injected intravenously in group I. In group II, patients are given ketamine $0.25 \mathrm{mg} / \mathrm{kg}$ plus propofol $1 \mathrm{mg} / \mathrm{kg}$. The bispectral index values, intraoperative hemodynamic changes, respiratory profiles, visual analog scale pain score, and adverse events were recorded. Results: No statistically significant difference between both groups regarding bispectral index values, hemodynamics, respiratory profiles, and visual analog scale pain score. The time needed to discharge patients from the postanesthetic care unit was prolonged in group I (39 $\mathrm{min}$ ) compared with group II (32 $\mathrm{min}$ ). Recovery agitation was reported in 5 patients in group I.

Conclusion: Both concentrations of ketamine and propofol are effective and safe in the sedation of obese patients. It is recommended to use the combination of ketamine and propofol $(\mathrm{k} / \mathrm{p} 1: 4)$ because this concentration is associated with a short recovery and less psychotomimetic side effects.
\end{abstract}

Keywords: ketamine; Propofol; Ketofol; Morbid obesity; Upper endoscopy

\section{INTRODUCTION}

Procedural sedation and analgesia (PSA) are the use of sedative drugs with or without analgesics to induce effective performance of diagnostic or therapeutic procedures. ${ }^{1}$

Many agents were successfully used to achieve PSA. Examples include benzodiazepines, ketamine, propofol, fentanyl, dexmedetomidine, and remifentanil. $^{2}$
Disclosure: The author has no financial interest to declare in relation to the content of this article. The Article Processing Charge was paid for by the author.

Authorship: Single Author . 
The most common adverse event of propofol is respiratory depression. Fortunately, the respiratory depression is decreased if the propofol dose is less than $0.7 \mathrm{mg} / \mathrm{kg},{ }^{6}$ and the dose of ketamine does not exceed $1 \mathrm{mg} / \mathrm{kg}$. ${ }^{7}$

The level of sedation can be detected clinically and be assessed with the bispectral index device (BIS). ${ }^{8}$

\section{The aim of the study}

The aim is to compare two different concentrations of ketofol used as sedation in morbidly obese adult patients scheduled for diagnostic upper GI endoscopy procedures.

The primary outcome is the drug effectiveness detected by the sedation level as measured by BIS values.

The secondary outcomes are the data collected to evaluate the safety of the drug: hemodynamic changes, respiratory profiles, emergence reactions, the time needed to discharge patients from the post anesthesia care unit (PACU), and any adverse events.

\section{Sample size calculation:}

Ninety-six patients were finalized as a sample size after a pilot study ( $\alpha=0.05, \beta=0.2)$. One hundred patients were selected to account for any reduction. After that patients randomized into two groups using a table of randomization with matching ages $(\mathrm{p}=0.893)$ and sexes $(\mathrm{p}=0.671)$.

\section{PATIENTS AND METHODS}

\section{Study design}

This prospective randomized single-blinded clinical study included 100 morbidly obese patients (BMI more than 35), prepared for diagnostic upper gastrointestinal endoscopy under sedation with ketamine and propofol combination.

\section{Study setting and population}

According to the American Society of Anesthesiologists (ASA) the patients were class II and III and allocated by a computer-generated random number table into two equal groups. Group I (ketamine to propofol 1:1), $\mathrm{n}=50$, and group II (ketamine to propofol 1:4), $n=50$.

Informed patient consent was obtained, and research and ethics committee approval was received according to the Helsinki Declaration of 1975, as revised in 2000.

The study was performed in the endoscopy area of Al-Hayat private hospital, Jeddah, KSA during the period from June 2018 to June 2019.

\section{Exclusion criteria}

Patients with ASA class more than III, age less than 21 or more than 55 years, pregnancy, drug abuse, drug allergy, bradyarrhythmia, heart, or lung disease. Study protocol

The patient monitor was connected (Infinity Delta Monitor; Draeger Medical System Inc., Danvers, MA 01923 USA). Mean arterial blood pressure (MAP), heart rate (HR), capillary oxygen saturation $(\mathrm{SpO} 2)$, and nasal cannula for end-tidal $\mathrm{CO} 2$ (EtCO2) were attached to the patients. The sedation level was measured by the BIS device (A-2000XP; Aspect Medical System, Covidien, Singapore).

The BIS values, hemodynamic changes (HR, MAP), and respiratory parameters (RR, $\mathrm{SpO} 2, \mathrm{EtCO} 2)$ were recorded every 5 min during the sedation period and in the PACU. The baseline readings were recorded 1 min before the initiation of topical anesthesia and sedation.

Later on, data collected and we compared the two groups at 3-time points: 1 . At baseline (before injection of drugs), 2. during endoscopy (5 min after induction), and 3 . at the PACU (15 min after shifting the patient to the recovery room).

Each patient has received glycopyrrolate $4 \mu \mathrm{g} / \mathrm{kg}$ and ondansetron $0.1 \mathrm{mg} / \mathrm{kg} \mathrm{IV}$ after the baseline reading. At the same time, a local anesthetic (lidocaine) ointment and spray were also given. After about 30 seconds from the injection of the sedation drug, the endoscope was inserted.

In separate syringes, the group I patients was given ketamine $1 \mathrm{mg} / \mathrm{kg}$ plus propofol $1 \mathrm{mg} / \mathrm{kg} \mathrm{IV}$, and in group II was given ketamine $0.25 \mathrm{mg} / \mathrm{kg}$ plus propofol $1 \mathrm{mg} / \mathrm{kg}$ IV. The BIS values kept between 70 and $80 .^{9}$

In the PACU, the patients were evaluated by the fasttrack score or criteria to document adequate recovery before the transfer of a patient to the ward. The total fast-tracks criteria of 14 , and 12 is the minimum score. No each score below one is allowed before discharging the patient from the PACU. ${ }^{10}$

Pain intensity was measured by a VAS pain score. We use a VAS ruler 0-10. Zero represented no pain and a ten the worst pain.

Agitation was measured by the Richmond AgitationSedation Scale.11 Any adverse events were documented as hypotension, bradycardia, desaturation, apnea, airway obstruction, seizure, visual disturbances, or postoperative nausea and vomiting (PONV).

\section{Statistical analysis}

Statistical analysis of the data done using Statistical Package for the Social Sciences, version 16.0 (SPSS Inc., USA) for Windows (Microsoft Co., USA). The data were presented as mean \pm standard deviation, or number and percentages. The data were compared using Fisher's exact, Student's t, and $\chi 2$ tests.

Ethical considerations: The study was approved by the ethical committee of Al-Azhar University, , Egypt. Verbal and written consent was taken from all participants and they were free to leave the study at any time.

\section{RESULTS}

The demographic data (age, sex, BMI, and ASA class) are represented in Table (1) and show no significant difference between the two groups.

Both MAP and HR decreased during the sedation period in group II compared with group I. This decrease was not quite statistically significant (pvalue 0.055 and 0.076 , respectively).

Regarding RR, SpO2, and $\mathrm{EtCO}$, there were no significant differences between group I, and group II. One patient in group II (no patient in group I) developed airway obstruction with no significant differences as shown in Table (2). No patients required manual ventilation.

Table (3) shows no significant differences between both groups regarding BIS and VAS.

The time needed to discharge the patients from the PACU was prolonged in group I (mean $\pm \mathrm{SD}=39 \pm$ $5.0 \mathrm{~min}$ ) compared with group II (mean $\pm \mathrm{SD}=32 \pm$ 3.9 min) with P-value 0.0001 (Table 4). 
The visual disturbances recorded $32 \%$ in group I and $18 \%$ in group II Table (5). Recovery agitation was more frequent in group I (5 patients or 10\%) compared with no patients in group II, P-value 0.056. Annoying dreams and hallucinations only reported in one patient $(2 \%)$ in group I.

\begin{tabular}{|c|c|c|c|}
\hline Characteristics & $\begin{array}{c}\text { Group } \\
\text { I }\end{array}$ & $\begin{array}{c}\text { Group } \\
\text { II }\end{array}$ & P-value \\
\hline Age (ys) & $29 \pm 7.3$ & $30 \pm 7.6$ & $0.50(\mathrm{NS})$ \\
\hline Sex (m/f) & $21 / 29$ & $25 / 25$ & $0.54(\mathrm{NS})$ \\
\hline Weight (kg) & $95 \pm 14$ & $98 \pm 14$ & $0.28(\mathrm{NS})$ \\
\hline BMI (kg/m2) & $36 \pm 2.5$ & $36 \pm 2.8$ & $1.00(\mathrm{NS})$ \\
\hline $\begin{array}{c}\text { ASA Class } \\
\text { (ASA II/III) }\end{array}$ & $34 / 16$ & $29 / 21$ & $0.40(\mathrm{NS})$ \\
\hline
\end{tabular}

Table (1): Demographic data

Data expressed as Mean \pm Standard deviation or number (percent).

ASA = American Society of Anesthesiologists

BMI $=$ body mass index

\begin{tabular}{|c|c|c|c|c|c|c|}
\hline \multirow{2}{*}{\multicolumn{2}{|c|}{ Characteristics }} & \multicolumn{2}{|c|}{ Group I } & \multicolumn{2}{|c|}{ Group II } & \multirow{3}{*}{$\begin{array}{l}\text { P-value } \\
0.20(\mathrm{NS})\end{array}$} \\
\hline & & \multirow{2}{*}{$\begin{array}{c}\text { Mean } \\
73\end{array}$} & \multirow{2}{*}{$\begin{array}{l}\text { SD } \\
3.8\end{array}$} & \multirow{2}{*}{$\begin{array}{c}\text { Mean } \\
74\end{array}$} & \multirow{2}{*}{$\begin{array}{l}\text { SD } \\
4.1\end{array}$} & \\
\hline \multirow{3}{*}{ HR } & At baseline & & & & & \\
\hline & during sedation & 71 & 5.11 & 69 & 6.01 & 0.076 \\
\hline & At PACU & 73 & 6.4 & 71 & 5.8 & $0.10(\mathrm{NS})$ \\
\hline \multirow{3}{*}{ MAP } & At baseline & 106 & 6.8 & 104 & 8.2 & 0.18 (NS) \\
\hline & During sedation & 100 & 7.8 & 97 & 7.7 & 0.055 \\
\hline & At PACU & 107 & 8.12 & 105 & 7.95 & $0.21(\mathrm{NS})$ \\
\hline \multirow{3}{*}{$\mathbf{R R}$} & At baseline & 16 & 2.3 & 16 & 2.1 & $1.00(\mathrm{NS})$ \\
\hline & During sedation & 17 & 3.3 & 16 & 3.1 & $0.12(\mathrm{NS})$ \\
\hline & At PACU & 17 & 1.6 & 17 & 1.8 & 1.00 (NS) \\
\hline \multirow{3}{*}{$\mathrm{SpO}_{2}$} & At baseline & 97.35 & 2.42 & 97.81 & 2.16 & $0.318(\mathrm{NS})$ \\
\hline & During sedation & 97.76 & 2.12 & 97.58 & 2.32 & 0.686 (NS) \\
\hline & At PACU & 98.22 & 1.79 & 98.01 & 1.88 & $0.568(\mathrm{NS})$ \\
\hline \multirow{3}{*}{ EtCO2 } & At baseline & 39 & 2.0 & 39 & 1.8 & $1.00(\mathrm{NS})$ \\
\hline & During sedation & 42 & 2.8 & 41 & 3.0 & 0.08 (NS) \\
\hline & At PACU & 38 & 2.9 & 37 & 3.1 & 0.09 (NS) \\
\hline
\end{tabular}

Table (2): Hemodynamic and respiratory parameters

Data expressed as Mean \pm Standard deviation.

MAP $=$ mean arterial pressure, $\mathbf{H R}=$ heart rate, $\mathbf{R R}=$ Respiratory Rate

$\mathbf{S p O}_{2}=$ Capillary oxygen saturation, EtCO2 $=$ end-tidal carbon dioxide pressure

\begin{tabular}{|l|l|c|c|c|c|c|}
\hline & & \multicolumn{2}{c}{ Group I } & \multicolumn{2}{c}{ Group II } & \multirow{2}{*}{ P-value } \\
\hline \multirow{2}{*}{ Characteristics } & Mean & SD & Mean & SD & \\
\hline BIS & Baseline & 98 & 1.49 & 98 & 1.45 & $1.00(\mathrm{~N})$ \\
\hline & During sedation & 82 & 3.9 & 81 & 3.7 & $0.19(\mathrm{~N})$ \\
\hline VAS & At PACU & 3.28 & 1.31 & 3.57 & 1.31 & $0.27(\mathrm{~N})$ \\
\hline
\end{tabular}

Table (3): Bispectral index and VAS pain score

Data expressed as Mean \pm Standard deviation

VAS = visual analog scale pain score, $\mathbf{B I S}=$ Bispectral index values

\begin{tabular}{|l|c|c|c|}
\hline \multicolumn{1}{|c|}{ Characteristics } & Group I & Group II & P-value \\
\hline Number of patients given top-up doses & $25(50 \%)$ & $29(58 \%)$ & 0.54 (NS) \\
\hline Propofol top-up dose (mg) & $45 \pm 9$ & $47 \pm 4$ & 0.15 (NS) \\
\hline Procedure duration (min) & $18 \pm 4.1$ & $19 \pm 3.6$ & 0.198 (NS) \\
\hline Recovery duration in PACU (min) & $39 \pm 5.0$ & $32 \pm 3.9$ & 0.0001 \\
\hline
\end{tabular}

Table (4): Operative data

Data expressed as Mean \pm Standard deviation or number (percent), PACU is posted anesthesia care unit 


\begin{tabular}{|c|c|c|c|}
\hline & Group I & Group II & P-value \\
\hline Agitation, (n) & $5(10 \%)$ & $0(0 \%)$ & 0.056 \\
\hline Hallucination, (n) & $1(2 \%)$ & $0(0 \%)$ & $1.00(\mathrm{NS})$ \\
\hline Nystagmus, (n) & $14(32 \%)$ & $9(18 \%)$ & $0.34(\mathrm{NS})$ \\
\hline Airway obstruction(n) & $0(0 \%)$ & $1(2 \%)$ & $1.00(\mathrm{NS})$ \\
\hline PONV, (n) & $3(4 \%)$ & $3(4 \%)$ & $1.00(\mathrm{NS})$ \\
\hline
\end{tabular}

Table (5): Postoperative adverse events

Data expressed as number (percent)

PONV = Postoperative nausea and vomiting

\section{DISCUSSION}

Many studies have shown that sedation with ketamine and propofol combination is effective and safe. In this study, a smaller dose of ketamine combined with propofol in group I was effective and safe, keep the respiratory and hemodynamic profiles stable with decreased incidence of adverse reactions. Behzad et al. performed a randomized clinical trial on 64 adult patients with breast cancer lumpectomy using ketamine and propofol combination (ketofol) compared to fentanyl and propofol combination (fentofol). They reported that both ketofol and fentofol are safe and effective with minimal adverse effects, but ketofol is a superior alternative to fentofol regarding respiratory depression. ${ }^{12}$

Ayatollah et al. conducted a study on two concentrations of ketamine and propofol in 100 patients for closed reduction of the nasal bones. The patients received either a ketamine/propofol combination $1: 3$ or $1: 1$. There was a decrease in recovery time, hallucination, and vomiting in the low dose ketamine group compared with the other group. ${ }^{13}$

Miner et al. made a study on 271 adults in the emergency department who underwent deep sedation received two doses of ketamine and propofol. They showed a similar airway and respiratory adverse events in ketofol 1:1 and 1:4 concentrations. ${ }^{14}$

Coulter et al. assessed different doses of ketofol for PSA in pediatrics and concluded that ketamine and propofol 1:3 combination was the suitable and greater concentration lead to prolonged recovery. ${ }^{15}$

Dal et al. studied two combinations; ketamine /propofol and ketamine/midazolam for PSA in adult patients and showed that the duration of recovery in a group KM was longer than KP. No serious adverse events were observed. ${ }^{16}$

Ghadami et al. studied two concentrations of ketofol in 60 pediatric patients. They divided the patients into two groups of ketofol, and the results showed that the group 1:3 had less psychotomimetic adverse effects, shorter recovery time, and lower incidence of hallucination and nausea than group 1:2.17

Wang et al. compared the ketofol in different doses with propofol /fentanyl and propofol alone. The study showed that the incidence of respiratory depression and post-procedural dizziness were lower in the low-dose ketamine group. ${ }^{18}$

Amornyotin et al. evaluated ketofol versus propofol alone as a sedative agent for patients with colonoscopy procedures and reported that no significant differences in patient satisfaction, hemodynamic changes, and recovery time. ${ }^{19}$
Kayhan et al. investigated the effect of ketofol versus propofol alone for electroconvulsive therapy. They found that the hemodynamic parameters were stable in the ketofol group. ${ }^{20}$

Hashemi et al. studied two different concentrations of ketofol in children and reported that recovery time and adverse events were reduced in low ketamine concentration group. ${ }^{21}$

Phillips et al. studied propofol monotherapy versus ketofol in PSA and concluded that sedation with ketofol was adequate but propofol alone need deep sedation level. ${ }^{22}$

Akin et al. studied ketofol versus propofol alone in 60 pediatric patients. They concluded that using ketamine in small dose with propofol maintain hemodynamic and respiratory stability with fewer complications. ${ }^{23}$

They also studied sedation with fentofol versus ketofol in 40 adults and found that the recovery time was similar in both groups, but the adverse events were more common in the ketofol group. ${ }^{24}$

Friedberg barry studied ketofol in 1264 patients for PSA and reported that ketofol is effective and safe medication. $^{25}$

\section{CONCLUSION}

The two concentrations of ketamine and propofol, $1: 1$, and 1:4 was effective and safe for sedation in morbidly obese adult patients. The ketamine in low concentration shortens the time to discharge and minimizes the psychological adverse effects.

Financial support and sponsorship: Nil.

No conflicts of interest.

\section{REFERENCES}

1. Green S, Krauss B. Procedural sedation terminology: moving beyond 'conscious sedation'. Ann Emerg Med 2002; 39:433.

2. Panzer O, Moitra V, Sladen R. Pharmacology of sedative-analgesic agents: dexmedetomidine, remifentanil, ketamine, volatile anesthetics, and the role of peripheral mu antagonists. Crit Care Clin, 2009; 25:451-69.

3. Chen W, Lin H, Zhang W, et al. Sedation and safety of propofol for therapeutic endoscopic retrograde cholangiopancreatography. Hepatobiliary Pancreat Dis Int, 2005; 4:437-40.

4. See C, Mensah E, Olopade C. Obesity, ethnicity, and sleep-disordered breathing: 
medical and health policy implications. Clin Chest Med, 2006; 27: 521-33.

5. Amornyotin S. Ketofol: A combination of ketamine and propofol. J Anaesth Crit Care, 2014; 1(5): 00031.

6. Smith I, Monk T, White P, et al. Propofol infusion during regional anesthesia: sedative, amnestic and anxiolytic properties. Anesth Analg, 1994; 79:31339.

7. Schuttler J, Zsigmond E, White P. Ketamine and its isomers. In: White PF, ed. Textbook of intravenous anesthesia. Baltimore, MA: Williams \& Wilkins, 1997. 171-88

8. Struys M, Verstichelen L, Byttebier G, et al. Clinical usefulness of the bispectral index for titrating propofol target effectsite concentration. Anesthesia, 1998; 53:412.

9. Kelley S. Monitoring consciousness using the bispectral Index TM (BISTM) during anesthesia; a pocket guide for clinicians. 2nd ed. Covidien, Gunbarrel Avenue Boulder, CO 80301 USA, 2007. 13 -14.

10. Dajun P. New criteria for fast-tracking after outpatient anesthesia: a comparison with the modified Aldrete's scoring system. Anesth Analg, 1999; 88:1069-72.

11. Curtis N, Mark S, Mary J, et al. The Richmond Agitation-Sedation Scale. American Journal of Resp and Crit Care Med, 2002; 166: 1338-44.

12. Behzad N, Mohammad M, Hamidreza S, et al. Comparison of Propofol and Ketamine Combination (Ketofol) and Propofol and Fentanyl Combination (Fenofol) on Quality of Sedation and Analgesia in the lumpectomy. Adv Biomed Res, 2018; 7:134.

13. Ayatollah V, Vafaiyan M, Hatami M, et al. Two different concentrations of ketofol for procedural sedation and analgesia in the closed reduction of the nasal fracture. $J$ Craniofacial Surg, 2016; 27:996-1000.

14. Miner J, Moore J, Austad E, et al. Randomized, a double-blinded clinical trial of propofol, 1:1 propofol/ketamine, and 4:1 propofol/ketamine for deep procedural sedation in the emergency department. Ann Emerg Med, 2015; 65:479-88.

15. Coulter S, Hannam A, Anderson J. Ketofol dosing simulations for procedural sedation. Pediatr Emerg Care, 2014; 30:621-30.

16. Dal $T$, Sazak $H$, Tunc $M$, et al. A comparison of ketamine-midazolam and ketamine-propofol combinations used for sedation in the endobronchial ultrasoundguided transbronchial needle aspiration: a prospective, single-blind, randomized study. J Thorac Dis, 2014; 86:742-51.

17. Ghadami Y, Ayatollahi V, Hashemi A, et al. Effect of two different concentrations of propofol and ketamine combinations
(Ketofol) in pediatric patients under lumbar puncture or bone marrow aspiration. Iran J Pediatr Hematol Oncol, 2013; 3:187-92.

18. Wang Y, Jiang X, Pang L, et al. A randomized, double-blind controlled study of the efficacy of ketofol with propofolfentanyl and propofol alone in termination of pregnancy. Afr J Pharm, 2012; 6:251014.

19. Amornyotin S, Chalayonnawin W, Kongphlay S. Clinical efficacy of the combination of propofol and ketamine (ketofol) for deep sedation for colonoscopy. Gut, 2012; 61: A339-40.

20. Kayhan G, Yucel A, Colak Y, et al. Ketofol (mixture of ketamine and propofol) administration in electroconvulsive therapy. Anaesth Intensive Care, 2012; 40:305-10.

21. Hashemi A, Ayatollah V, Ghilian R, et al. Ketofol for bone marrow aspiration and lumbar puncture in children with ALL. Iran J Pediatr Hematol Oncol, 2011; 1:126-32.

22. Phillips W, Anderson A, Rosengren M, et al. Propofol versus propofol/ketamine for brief, painful procedures in the emergency department: clinical and bispectral index scale comparison. J Pain Palliat Care Pharmacother, 2010; 24:349-55.

23. Akin A, Esmaoglu A, Guler $G$, et al. Propofol, and propofol/ketamine in pediatric patients undergoing cardiac catheterization. Pediatr Cardiol, 2005; 26:553-57.

24. Akin A, Guler G, Esmaoglu A, et al. A comparison of fentanyl/propofol with a ketamine/propofol combination for sedation during endometrial biopsy. J Clin Anesth, 2005; 17:187-90.

25. Friedberg Barry L. Propofol/ketamine technique: dissociative anesthesia for office surgery (a 5-year review of 1264 cases). Aesth Plast Surg, 1999; 23:70-75. 